\title{
Osteoporotic vertebral collapse with late neurological complications
}

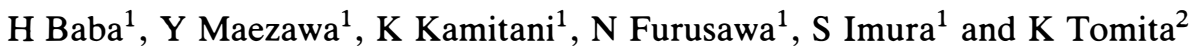 \\ ${ }^{1}$ Department of Orthopaedic Surgery, Fukui Medical School, Shimoaizuki 23, Matsuoka, Fukui 910-11, Japan; \\ ${ }^{2}$ Department of Orthopaedic. Surgery, School of Medicine, Kanazawa University, Takaramachi 13-1, Kanazawa \\ 920, Japan
}

\begin{abstract}
This paper describes 27 patients who had a spinal fracture and underwent an anterior or a posterior spinal decompression, with or without spinal instrumentation, for late neurological compromise secondary to post-traumatic vertebral collapse associated with osteoporosis. Five males and 22 females were studied, with an average follow-up of 3.7 years. The patients developed delayed neurological compromise due to osteoporotic vertebral collapse 1 month to 1.5 years following insignificant spinal fractures. Abnormal hypermobility at the collapsed spinal level with gradual retropulsion of fracture fragments into the spinal canal appeared to contribute to late paralysis. This pathology is treated surgically either anteriorly or posteriorly, but we recommend transpedicular posterolateral decompression and stabilization with a screw-rod construct because of technical ease and minimum invasion.
\end{abstract}

Keywords: spinal fracture; osteoporosis; late paraparesis; kyphosis; spinal instrumentation

\section{Introduction}

Osteoporosis is a major cause of spinal compression fractures in the elderly. Despite an extremely high incidence of spinal fracture in such people, immediate neurological compromise after trauma is uncommon. A simple compression fracture is most frequent, usually manifesting no serious spinal canal compromise or resulting spinal instability. However, a series of spinal fractures in those with osteoporosis can gradually result in serious impingement on neural tissues anteriorly and cause subsequent late devastating neurological compromise mostly with a kyphotic deformity. ${ }^{1-4}$ Current literature concerning this type of uncommon spinal injury is limited, but appears to be increasing. However the mechanism causing such late neurological sequelae is still poorly understood. ${ }^{5-9}$ We report 27 patients who underwent decompressive and reconstructive surgery for late neurological compromise secondary to this spinal problem, termed osteoporotic vertebral collapse, and discuss the possible mechanism causing paralysis.

\section{Patients and methods}

Between 1981 and 1992, 29 patients with late neurological deficits associated with osteoporotic vertebral collapse were treated surgically at our university hospitals and affiliated institutions. Two of them had died, we found, and the other 27 patients, comprising five males and 22 females, were studied. The age at surgery ranged from 53 to 82 (average: 61). Osteoporo- sis was classified as postmenopausal in 21 patients, senile in four, and corticosteroids-induced in two. Owing to the delay in symptomatic onset and even in diagnosis, the duration between back trauma and symptomatic onset was estimated at from 1 month to 1.5 years (average: 5.3 months). No major vertebral trauma manifested immediate paralysis. All of the patients were initially treated conservatively, but vertebral collapse progressed gradually with resulting neurological symptoms. Two patients were incorrectly operated on (in outside institutions), for lumbar spinal stenosis, not for osteoporotic vertebral collapse. The patients were followed up from 1.3 to 6.6 years (average: 3.7 years): some were evaluated by the examination chart at their last visit.

\section{Neurological examination}

Pain and the neurologic status were assessed by the system shown in Table $1 .{ }^{10}$ Preoperative, localized, and incapacitating spinal pain in relation to the collapsed vertebra occurred in 17 patients. The patients' histories revealed symptomatic lumbar spinal stenosis requiring no surgical intervention in seven, mild Parkinsonism in two, a minor stroke in two, and mild diabetic neuropathy in one patient. Spinal cord and cauda equina symptoms and signs were variable and required repeat confirmation; sensory disturbance was present in all of the patients; muscle weakness in 18; hyperactive patellar tendon reflex in 13; Babinski's reflex in eight; and vesicorectal dysfunction in six. Excluding two patients who had undergone previous surgery for 
Table 1 Scoring system for assessing pain and neurological status

\begin{tabular}{ll}
\hline Categories & Score (point) \\
\hline Spinal pain & \\
Incapacitating and uncontrollable & 0 \\
Controllable with medication & 1 \\
Painful but no medication needed & 2 \\
$\quad$ Negligible or absent & 3 \\
Motor function in lower extremities & \\
Impossible to walk & 0 \\
Cane or aid on flat ground & 1 \\
Aid only on stairs & 2 \\
Walk unaided but slow & 3 \\
$\quad$ Normal & 4 \\
Sensory function & \\
Trunk & \\
$\quad$ Apparent & 0 \\
$\quad$ Minimal & 1 \\
$\quad$ Normal & 2 \\
Lower extremity & \\
$\quad$ Apparent & 0 \\
$\quad$ Minimal & 1 \\
$\quad$ Normal & 2 \\
Bladder function & \\
Urinary retention or incontinence & 0 \\
Severe dysuria (sense of retention) & 1 \\
Slight dysuria (pollakisuria, retardation) & 2 \\
Normal & 3 \\
\hline
\end{tabular}

Normal $=\mathrm{a}$ total of the best scores: $(1+2+3+4)=14$ points

lower-lumbar spinal stenosis, $16(59 \%)$ had gradual deterioration of muscle tone and of motor power following their back trauma, mainly distal to the knees. Further, excluding two patients who had had a stroke, $11(41 \%)$ patients with hyperactive patellar tendon reflexes as well as six $(22 \%)$ with a positive Babinski's reflex were considered to have progressed neurologically in association with osteoporotic vertebral collapse. No patient had sensory or motor difficulties in the lower extremities directly caused by Parkinsonism or diabetes mellitus. Three of the five male patients had prostate hypertrophy, two of whom had been treated surgically before admission. The patient's pain and neurological scores at follow-up determined the postoperative improvement rate as follows: postoperative score minus preoperative score, divided by 14 minus preoperative score, multiplied by $100(\%)$. The result was assessed as excellent with improvement rate $\geqq 80 \%$; good $50-79 \%$; fair $25-49 \%$ and poor $\leqq 24 \%$.

\section{Radiological examination}

Diagnostic radiology included plain radiography, tomography, myelography, computed tomographic myelography (CT: GE CT/T 8800, General Electric, Milwaukee, WI, USA) and in some patients, magnetic resonance imaging (MRI: GE 1.5 Tesla Signa System,
General Electric, Milwaukee, WI, USA) from 1985. Vertebral osteoporosis was diagnosed primarily by conventional radiography in the 18 early patients, demonstrating diminished trabecular patterns transversely, then vertically, evidence of a single or of multilevel biconcave or wedge-shaped vertebral fractures, and multilevel loss of vertebral body height in conjunction with kyphotic and/or round-back deformity. In the nine late patients, the pathology was also assessed additionally by dual energy X-ray absorptiometry (Hologic QDR 1000, Waltham, MA, USA). The average and standard deviation in vertebral mineral density of the collapsed vertebra in these patients was $0.712 \pm 0.138 \mathrm{~g} \mathrm{~cm}^{-2}$. The modality of vertebral injury on admission was classified as unstable wedge compression fracture seen in three patients; or burst fracture by the Denis ${ }^{11}$ classification, seen in 24 . A single vertebra collapsed in 23 patients and four had involvement of two vertebrae: T11 and L1 vertebrae in two patients, and T12 and L1 in two. The eleventh vertebra collapsed in five patients, T12 in eight, L1 in six, L2 in two, L4 in one, and L5 in one. Kyphosis was measured between the upper and lower surfaces of the vertebral bodies above and below the collapsed vertebra. To investigate spinal movement at the collapsed level, the minimum vertebral body height (a in Figure 1) at the middle portion of the vertebral body ${ }^{12}$ was measured in flexion-extension lateral radiographs. Maximum canal compromise (b in Figure 1) by the retropulsed fragment was also measured in flexionextension lateral radiographs. All radiographic measurements were conducted directly on radiographs, with the distance from the radiation source to the film tray being set approximately at $100 \mathrm{~cm}$ and the film being in contact with the lateral side of the patient's trunk. Three examiners (YM, KK, and NF) were involved in radiographic measurements, and the mean values measured were analysed statistically.

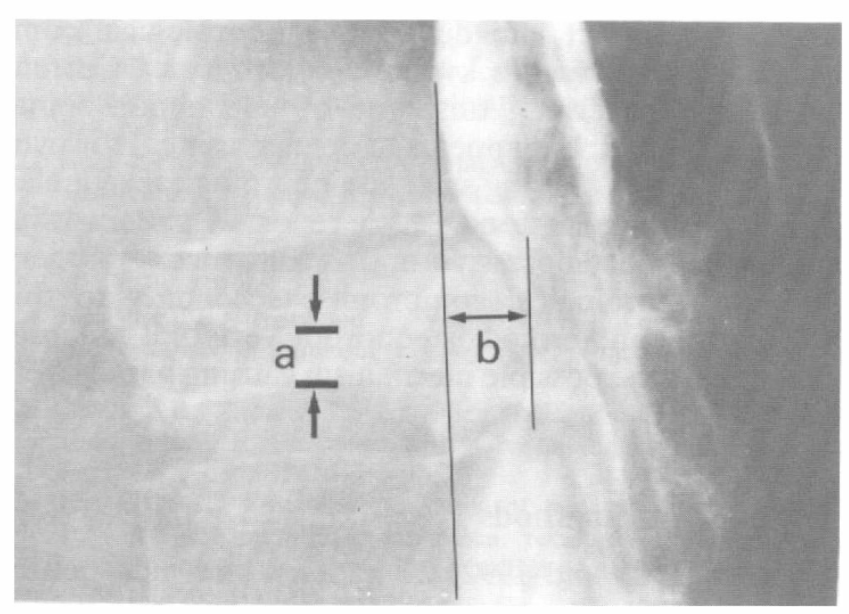

Figure 1 Myelogram in case 18 showing the method of measuring minimum vertebral body height and maximum canal compromise. Abbreviations: a, minimum vertebral body height; b, maximum canal compromise (drawings made by a Mac computer) 
Preoperative histological examination

The diagnosis of osteoporotic vertebral collapse was made primarily by the radiological appearances, but, in some patients (cases $6,7,12,14$, and 18 in Table 2), a preoperative histological examination was necessary to differentiate the pathology from primary tumour, metastasis, or spondylitis. Transpedicular biopsy under local anaesthesia using an image intensifier confirmed the presence of osteoporosis in all of the subjects. Typical histological findings included reduced bony trabeculae and increased necrotic bone and cicatrix tissue without any evidence of vascularisation or cellular proliferation usually seen in the normal fracture healing. Postoperatively, histological findings confirmed that there was no evidence of pathology other than that of osteoporosis in 10 patients; in 12 other patients, however, no tissue diagnosis was made.

\section{Surgery}

Surgery was indicated for all patients with progressive neurological problems, mostly accompanied by spinal pain and a kyphos. There were different types of surgery, utilising the technical advances in spinal instrumentation. No serious major complications occurred related either to surgery or to anaesthesia. Table 2 gives the demographic data.

Anterior surgery was performed in seven patients: Kaneda instrumentation in four, Zielke VDS in two, and anterior fusion alone in one. Three patients had collapsed T12 vertebrae; three, L1; and one, L4. The T12 vertebra was exposed by extrapleural and extraperitoneal approaches, and extraperitoneal access was undertaken for L1 and L4 vertebrae. The affected vertebrae and paired discs, mostly retropulsed into the canal, were debrided followed by exposure of the dura mater and the use of spinal instrumentation with an iliac and/or a fibular autograft. The patient was allowed out of bed on the fourth day after surgery. The operation time for anterior surgery ranged from 3.7 to $5.5 \mathrm{~h}$ (average: $4.5 \mathrm{~h}$ ), and the blood loss 453 to $830 \mathrm{~g}$ (average: $530 \mathrm{~g}$ ).

Twenty patients underwent posterior transpedicular decompression with Cotrel-Dubousset (CD) instrumentation, which enables transpedicular posterolateral decompression and simultaneous correction of the kyphosis with the use of spinal implants, as Garfin et al ${ }^{13}$ Abitbol et al, ${ }^{14}$ and McCormick ${ }^{15}$ advocate. The affected vertebral body is approached posterolaterally, but the maximum amount of lamina is preserved to minimize subsequent instability; laminectomy of the affected level alone is usually appropriate. Pedicle screws $7 \mathrm{~mm}$ in diameter and $4.5-5 \mathrm{~cm}$ long are placed in one or two vertebrae above and below the affected level(s). Pediculotomy and medial facetectomy for the affected vertebral level only are sufficient to view and debride any osseous and disc fragments encroaching anteriorly on the spinal cord. Fragments are removed with a reverse-angle curette or drilled away with a surgical airtome, or impacted anteriorly with a pusher without manipulation of the spinal cord.
A 360-degree spinal cord decompression is thus implemented without any significant injurious manipulation of the spinal cord itself. After resection or firm impaction of the slightly bulged posterior vertebral wall anteriorly, sometimes with morcellised autogenous bone grafts into the fractured body, CD rods already contoured are applied to maintain the reduced position of the kyphosis as much as possible. Care was taken not to contour rods for greater correction after the setup of the entire assembly to avoid screw pullout from the vertebral bodies. Kyphosis is corrected essentially by postural reduction on the operating table. Laminar fusion is recommended throughout the areas instrumented, and costotransverse process fusion at the laminectomy and pediculotomy level is mandatory. In our series, the duration for posterior surgery ranged from 2.5 to $4.3 \mathrm{~h}$ (average: $3.3 \mathrm{~h}$ ), with a blood loss 210 to $330 \mathrm{~g}$ (average: $270 \mathrm{~g}$ ). The patient is allowed to move without a thoracolumbar orthosis on the second day after surgery.

\section{Statistical analysis}

The radiographic data measured and collected were stored as category scores in the StatView II ${ }^{\mathrm{TM}}$ program (Abacus Concepts, Berkeley, CA, USA) using a Macintosh LC630 computer (Apple, Cupertino, CA, USA). Statistical evaluations included non-parametric tests (Mann-Whitney, cumulative $\chi^{2}$, and KruskalWallis), with the $P$ value $<0.05$ viewed as significant.

\section{Results}

\section{Neurological outcome}

Overall results showed excellent neurological recovery in six patients, good in 15, fair in four, and poor in two (Table 2). Twenty-one (78\%) patients obtained good to excellent results. All patients with cauda equina deficits alone due to lower lumbar involvement had good to excellent results. The average score of all patients improved from 8.3 points preoperatively to 11.7 points at follow-up with an average improvement rate of $63.0 \%$. One patient (case 16) with double-level compromise continued to require catheterisation due to significant loss of voluntary bladder control, and two patients with Parkinsonism (cases 10 and 25) required temporary use of a walking aid despite good neurological improvement in the lower extremities postoperatively.

Patients younger than 59 years of age $(n=7), 60-69$ $(n=10)$, and 70 or older $(n=10)$ showed average neurological improvement rates of $71.5 \%, 60.8 \%$, and $56.4 \%$, but no statistical difference was observed among these groups (cumulative $\chi^{2}$ test). Furthermore, the duration of the paresis did not significantly affect their postoperative neurological improvement. Patients with preoperative scores of 7 or less $(n=9), 8-9$ $(n=12)$, and 10 or more $(n=6)$ showed average neurological improvement rates of $55.3 \%, 57.7 \%$, and $87.5 \%$, with the last group showing significant improvement (cumulative $\chi^{2}$ test, $\chi^{* 2}=7.165, P=0.009$ ). 
Table 2 Demographic data

\begin{tabular}{|c|c|c|c|c|c|c|c|c|c|}
\hline Case no. & $\begin{array}{l}\text { Age } \\
(y) / S e x\end{array}$ & $\begin{array}{l}\text { Affected } \\
\text { spinal level }\end{array}$ & $\begin{array}{c}\text { Duration of } \\
\text { disease history }\end{array}$ & $\begin{array}{l}\text { Type of } \\
\text { fracture }^{\mathrm{b}}\end{array}$ & $\begin{array}{l}\text { Operative } \\
\text { procedure }^{\mathrm{c}}\end{array}$ & $\begin{array}{l}\text { Preoperative } \\
\text { score }\end{array}$ & $\begin{array}{c}\text { Score at } \\
\text { follow-up }\end{array}$ & $\begin{array}{l}\text { Follow-up } \\
\text { period }(y)^{\mathrm{d}}\end{array}$ & Results \\
\hline 1 & $74 / \mathrm{M}$ & L1 & 5 & $\mathrm{~B}$ & Zielke & 6 & 10 & 5.3 & Good \\
\hline 2 & $63 / F$ & $\mathrm{~T} 12$ & 3 & $\mathrm{~B}$ & Zielke & 8 & 9 & 6.6 & Poor \\
\hline 3 & $59 / \mathrm{F}$ & $\mathrm{T} 12$ & 7 & $\mathrm{~B}$ & Anterior fusion alone & 8 & 13 & 6.3 & Excellent \\
\hline 4 & $75 / \mathrm{M}$ & L4 & 2 & $\mathrm{~B}$ & Kaneda & 9 & 13 & 5.8 & Excellent \\
\hline 5 & $62 / F$ & L1 & 1 & $\mathrm{~W}$ & Kaneda & 9 & 12 & 5.5 & Good \\
\hline 6 & $81 / F$ & $\mathrm{~T} 12+\mathrm{L} 1$ & 4.5 & $\mathrm{~B}$ & $\mathrm{CD}$ & 7 & 10 & 5.1 & Fair \\
\hline 7 & $61 / \mathrm{F}$ & $\mathrm{T} 11$ & 8 & W & $\mathrm{CD}$ & 9 & 10 & 4.9 & Poor \\
\hline 8 & $74 / F$ & $\mathrm{~T} 12$ & 15.5 & B & $\mathrm{CD}$ & 10 & 13 & 5.4 & Good \\
\hline 9 & $81 / \mathrm{F}$ & $\mathrm{L} 2$ & 3 & $\mathrm{~B}$ & $\mathrm{CD}$ & 7 & 11 & 4.8 & Good \\
\hline 10 & $62 / F$ & $\mathrm{~L} 1$ & 2 & $\mathrm{~B}$ & Kaneda & 8 & 11 & 4.5 & Good \\
\hline 11 & $75 / \mathrm{F}$ & $\mathrm{T} 12$ & 2 & B & Kaneda & 7 & 12 & 4.1 & Good \\
\hline 12 & $69 / \mathrm{F}$ & L2 & 18 & $\mathrm{~B}$ & $\mathrm{CD}$ & 10 & 14 & 3.9 & Excellent \\
\hline 13 & $58 / \mathrm{F}$ & $\mathrm{T} 11$ & 5 & $\mathrm{~B}$ & $\mathrm{CD}$ & 5 & 10 & 3.7 & Good \\
\hline 14 & 73/M & $\mathrm{T} 12$ & 2 & W & $\mathrm{CD}$ & 7 & 10 & 3.3 & Fair \\
\hline 15 & $68 / \mathrm{F}$ & $\mathrm{L} 1$ & 4 & B & $\mathrm{CD}$ & 9 & 13 & 3.1 & Good \\
\hline 16 & $72 / F$ & $\mathrm{~T} 11+\mathrm{L} 1$ & 2 & B & $\mathrm{CD}$ & 9 & 11 & 3.0 & Fair \\
\hline 17 & $82 / F$ & $\mathrm{~T} 11+\mathrm{L} 1$ & 7 & B & $\mathrm{CD}$ & 5 & 9 & 3.3 & Fair \\
\hline 18 & $63 / F$ & $\mathrm{~T} 12$ & 3 & B & $\mathrm{CD}$ & 9 & 12 & 2.9 & Good \\
\hline 19 & $54 / \mathrm{F}$ & T11 & 4 & B & $\mathrm{CD}$ & 10 & 14 & 2.7 & Excellent \\
\hline 20 & $58 / \mathrm{F}$ & $\mathrm{T} 12+\mathrm{L} 1$ & 3 & B & $\mathrm{CD}$ & 9 & 12 & 2.5 & Good \\
\hline 21 & $63 / \mathrm{F}$ & $\mathrm{T} 11$ & 4 & B & $\mathrm{CD}$ & 7 & 12 & 2.5 & Good \\
\hline 22 & $59 / \mathrm{M}$ & L1 & 14.4 & B & $\mathrm{CD}$ & 10 & 12 & 2.3 & Good \\
\hline 23 & 63/M & L5 & 3 & $\mathrm{~B}$ & $\mathrm{CD}$ & 11 & 14 & 2.1 & Good \\
\hline 24 & $72 / \mathrm{F}$ & $\mathrm{T} 12$ & 4 & B & $\mathrm{CD}$ & 9 & 12 & 1.9 & Good \\
\hline 25 & $63 / \mathrm{F}$ & T11 & 5 & $\mathrm{~B}$ & $\mathrm{CD}$ & 8 & 11 & 1.7 & Good \\
\hline 26 & $55 / \mathrm{F}$ & $\mathrm{T} 12$ & 8 & B & $\mathrm{CD}$ & 10 & 14 & 1.5 & Excellent \\
\hline 27 & $53 / F$ & L1 & 5 & B & $\mathrm{CD}$ & 9 & 13 & 1.3 & Excellent \\
\hline
\end{tabular}

amonths; ${ }^{\mathrm{b}} \mathrm{B}=$ burst fracture, $\mathrm{W}=$ wedge compression fracture; ${ }^{\mathrm{c}}$ Zielke and Kaneda instrumentation for anterior stabilisation, and $\mathrm{CD}$ (Cotrel-Dubousset instrumentation for posterior stabilisation; ${ }^{\mathrm{d} F o l l o w}$-up is the period from surgery to the final hospital visits 
Patients who had anterior spinal surgery had an average improvement rate of $58.6 \%$ and those who had posterior surgery $64.5 \%$, demonstrating no significant difference ( $P=0.0685$, Mann-Whitney).

\section{Radiographic study}

Findings in minimum vertebral body height, maximum canal compromise, and the kyphotic angle in flexion or extension are shown in Table 3. The minimum vertebral body height increased significantly in extension at level T11, compared to scores at other levels $(P=0.0387$, Mann-Whitney), with an average increment of $88 \%$. Maximum canal compromise by fractured fragments showed no remarkable change. Kyphosis was greatest in flexion at level T12 and incrementation of the angle was significant at T11 and T12 level (level T11: $P=0.0433$ concerning level L1, and level T12: $P=0.0317$ concerning level $\mathrm{L} 1$, Kruskal-Wallis).

Figure 2 shows changes of kyphotic angle in a neutral film preoperatively, postoperatively, and at follow-up. In the anterior surgery group, $40 \%$ of kyphosis was corrected immediately after surgery and $12 \%$ at follow-up; $38 \%$ correction was lost. In the posterior surgery group, the Kyphosis was corrected in $61 \%$ immediately after surgery and in $46 \%$ at follow-up. At follow-up, a loss of correction occurred in both groups, although this was less in patients undergoing posterior surgery, but not to a significant degree $(P=0.0773$, Mann-Whitney).

\section{Instrumentation failures}

In six cases with anterior spinal instrumentation, one with Zielke VDS fixation for an L1 unstable burst fracture showed a loose vertebral screw with dislodgement of a rod but an anterior strut graft united eventually without the necessity for refixation of implants. In 20 patients with CD instrumentation, three showed minor instrumentation failures during their postoperative course (loose screws from pedicles and bodies in two cases and bent screw-neck in one); none showed instrument-related neurological problems.

\section{Discussion}

Vertebral compression fracture is common in the elderly, and is usually well treated conservatively.

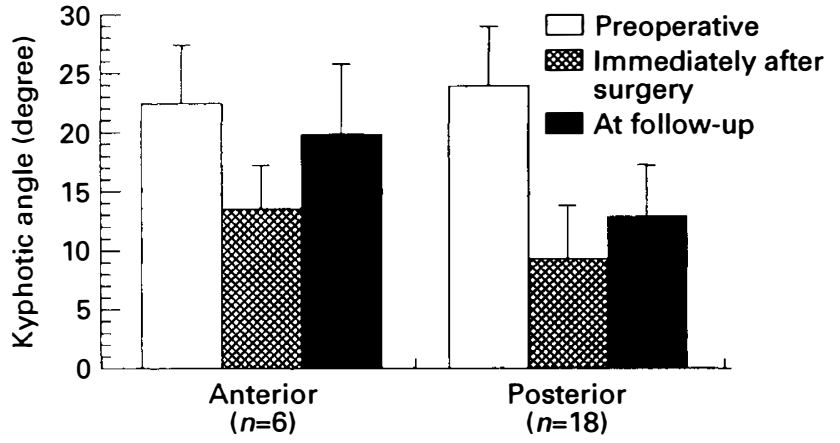

Figure 2 Changes in kyphotic angle at the affected spinal level before and after surgery and at follow-up, in anterior $(n=6)$ and posterior $(n=18)$ surgery for vertebral collapse between T11 and L2

Although an osteoporotic fracture rarely causes an acute neurological problem, late neurological difficulties are occasionally encountered. Less well understood is the modality of disruption of vertebral collapse even after a simple spinal fracture and resultant deformity in those with osteoporosis. The scope of this problem appears to be increasing as the population ages. ${ }^{16}$

In patients with a round back or a kyphosis secondary to osteoporosis, the injurious loading pattern is directed more axially and ventrally. The vertebra in osteoporosis is considered to reduce the trabecular pattern resistive to axial loads and the blood circulation to facilitate fracture healing. Repeated minor fractures, or even an inadequate bracing technique, may also delay fracture healing. A histological example obtained from the collapsed T12 vertebra in case 14 is shown in Figure 3, demonstrating abundant cicatrix tissue formation within more necrotic bone. The histology also demonstrates the lack of expected fracture healing patterns. Cicatrix tissue or fibrous granulation within the vertebral body is obviously unresistive to axial and flexural loads and subsequent segmental instability, while bony and disc fragments in posterior parts of the vertebra gradually migrate into the spinal canal. An increase in the kyphosis at the affected segment enhances this bony and cartilaginous retropulsion instead of fracture healing, accelerated by segmental instability developed gradually after trauma. Serial radiographic changes with gradual collapse and bony retropulsion seen in case 9 are shown in Figures $4 a-c$.

Table 3 Preoperative radiographic findings in minimum vertebral body height, maximum canal compromise and kyphotic angle

\begin{tabular}{|c|c|c|c|c|c|c|}
\hline \multirow[t]{2}{*}{$\begin{array}{l}\text { Affected } \\
\text { level }\end{array}$} & \multicolumn{2}{|c|}{$\begin{array}{l}\text { Minimum vertebral } \\
\text { body height }(\mathrm{mm})\end{array}$} & \multicolumn{2}{|c|}{$\begin{array}{l}\text { Maximum canal } \\
\text { compromise }(\mathrm{mm})\end{array}$} & \multicolumn{2}{|c|}{$\begin{array}{c}\text { Kyphotic } \\
\text { angle (degree) }\end{array}$} \\
\hline & Flexion & Extension & Flexion & Extension & Flexion & Extension \\
\hline $\begin{array}{l}\text { T11 }(n=5) \\
\text { T12 }(n=8) \\
\text { L1 }(n=6)\end{array}$ & $\begin{array}{r}8 \pm 3 \\
10 \pm 2 \\
7 \pm 2\end{array}$ & $\begin{array}{c}15 \pm 4^{*} \\
12 \pm 4 \\
9 \pm 3\end{array}$ & $\begin{array}{l}7 \pm 2 \\
7 \pm 3 \\
6 \pm 2\end{array}$ & $\begin{array}{l}6 \pm 2 \\
7 \pm 4 \\
5 \pm 2\end{array}$ & $\begin{array}{l}21 \pm 4^{* *} \\
26 \pm 5^{* * *} \\
18 \pm 3\end{array}$ & $\begin{array}{l}15 \pm 5 \\
13 \pm 3 \\
16 \pm 4\end{array}$ \\
\hline
\end{tabular}

Values are mean \pm standard deviation. ${ }^{*} P=0.0387$ (Mann-Whitney); ${ }^{* *} P=0.0433$ and ${ }^{* * *} P=0.0317$ (Kruskal-Wallis) 


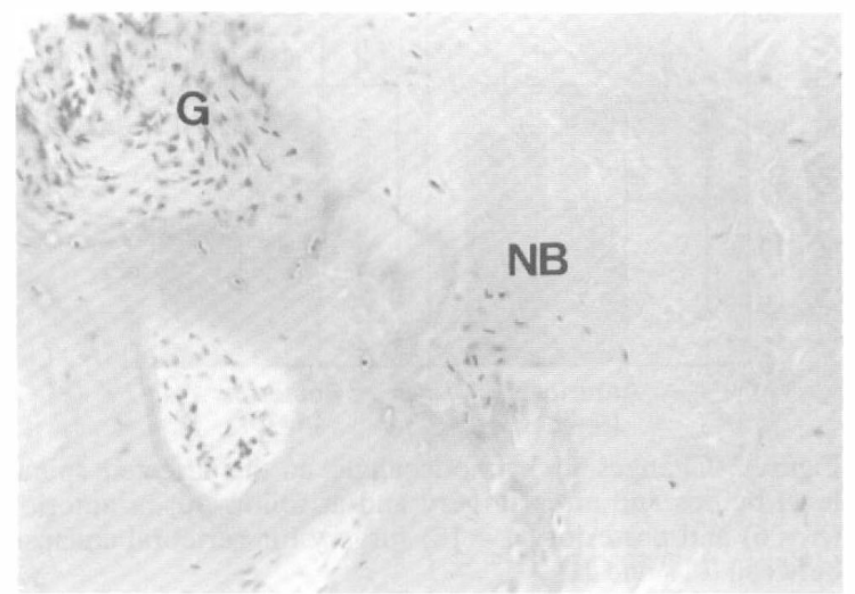

Figure 3 Fibrous granulation tissue within the collapsed vertebral body and necrotic bone (Hematoxylin and Eosin, $\mathrm{X} 40$ ). $\mathrm{G}=$ granulation tissue; $\mathrm{NB}=$ necrotic bone

These factors interact and may contribute to late neurological compromise. These possible causes may suggest the significance of valid external fixation facilitating fracture healing and minimising abnormal motion and subsequent segmental instability and preventing scar tissue formation within the affected vertebra. Our patients developed neurological symptoms approximately 6 months following trauma. Thus, as Kostuik $^{17}$ strongly suggests, careful observation must continue for at least 6 months after an osteoporotic fracture, with various modalities of medical management. ${ }^{18,19}$

The prediction of late neurological difficulties is by no means easy, but some risk factors are demonstrated by radiography. Our study suggested precipitating factors to be (1) vertebral fracture involving both the anterior and the posterior corpus, ie burst fracture; (2) increased kyphosis resulting from a wedge compression fracture (kyphotic angle measured at the affected spinal level more than 30 degrees); and (3) vacuum shadow within the fractured vertebral body potentially implying ischaemic necrosis of bone. Established kyphosis or round-back deformity may also facilitate fractured fragments to migrate into the spinal canal. Even if asymptomatic, patients with spinal cord compression demonstrated in MRI after trauma should also be followed up with the utmost care. Patients with asymptomatic retropulsed fragments appear to be highly prone to develop neurological compromise in the presence of increased segmental hypermobility or instability. Before the current review, we hypothesised that the posterior part of fractured fragments would impinge more prominently on the spinal cord when the spine was flexed, but no radiographic evidence obtained was able to verify this assumption.

Symptomatic evidence of spinal cord compromise is an affirmative indication for anterior or posterior decompression or for both. Reduced bone quality in the vertebrae is to be increased through spinal in- strumentation techniques. Kaneda et al ${ }^{20}$ advocate anterior decompression, bioactive ceramic vertebral prosthesis replacement, and the use of their unique spinal implants. ${ }^{21}$ They suggest that anterior route surgery secures complete decompression leading to satisfactory results with unexpectedly decreased invasion even in the elderly. They disagree with violation of the intact posterior spinal elements of the facets and laminae and interspinous ligaments for the prevention of segmental instability. Posterior decompression is easier to conduct, however. Transpedicular posterolateral or a 360 -degree circum-spinal approach ${ }^{22}$ provides direct access to the compressive lesion anterior to the spinal cord. Shikata et $a l^{23}$ excised retropulsed fragments satisfactorily posterolaterally, followed by Harrington instrumentation without correction of the kyphosis at the affected level. They attained better neurological results but, from a mechanical point of view, resultant kyphosis at the collapsed spinal level is best corrected. ${ }^{24}$ Transpedicular posterolateral decompression with stabilization by a screw-rod construct is easy and is preferred for correction of kyphosis and to enable early mobilization, $;^{25,26}$ however, loose transpedicular screws from the vertebral bodies with reduced bone quality may contribute to the prevention of correction of kyphosis and possible instrumentation failures. ${ }^{27}$ However, patients with CD instrumentation showed less loss of correction as expected, possibly due to the use of transpedicular screws with larger diameters, as is shown in Figures 5a and b. One earlier patient with L4 involvement underwent Kaneda instrumentation but, at present, we suggest that patients with a lower lumbar (L4 and L5) involvement are best operated on posteriorly with a screw-rod construct. To avoid possible screw pullouts the transpedicular use of methylmethacrylate bone cement within the vertebral bodies to secure the screw position is reported. In this kind of reinforcement, Shibata et al ${ }^{28}$ very recently reported that self-setting hydroxyapatite cement injected transpedicularly into the osteoporotic vertebral body in vivo successfully strengthens anchoring to withstand screw pullout and axial load. Transpedicular cement augumentation, however, to anchor the screws within the vertebral bodies is usually not necessary and, at present, we do not recommend the use of this technique, based on our experience with a CD construct in 20 cases.

\section{Conclusions}

Post-traumatic osteoporotic vertebral collapse follows a minor spinal injury with segmental hypermobility/ instability accompanied by absence of fracture healing. A variety of symptoms as late neurological sequelae must be diagnosed precisely so that surgical management is conducted earlier. Transpedicular decompression with posterior stabilization by a screw-rod construct offers a good chance for neurological improvement, simultaneously correcting the kyphotic deformity at the affected spinal level fairly well. 

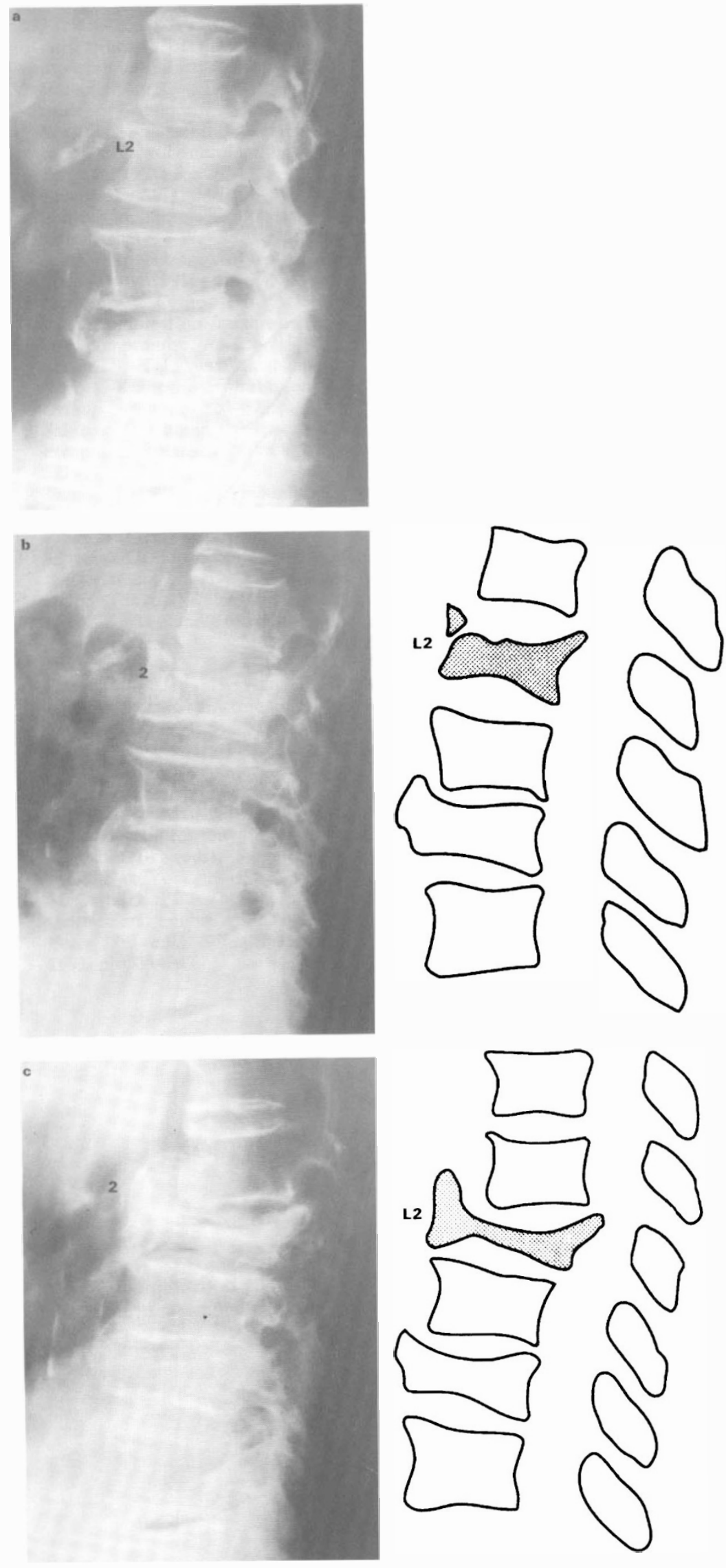

Figure 4 Radiographs of patient with collapsed L2 vertebra (case 9). (a) Minimal fracture at the superior endplate and subchondral area of the L2 vertebra. (b) Vertebral collapse 5 weeks later. (c) Marked vertebral collapse with retropulsion of the posterior wall into the spinal canal noted on admission 3 months after trauma. L4 vertebra already showing healing 

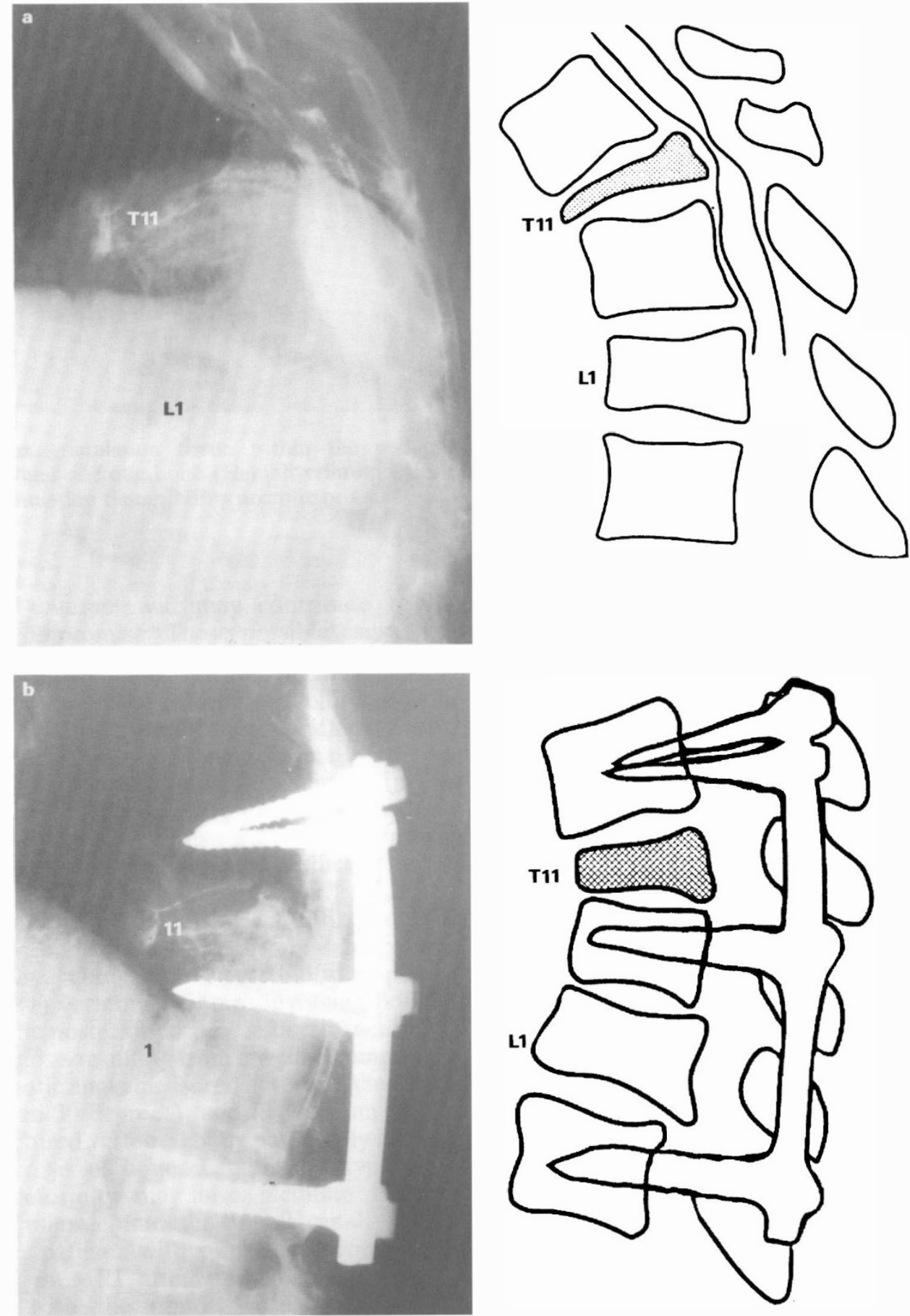

Figure 5 (a) Preoperative myelograph of case 17 showing osteoporotic vertebral collapse T11 and L1, both impinging on th spinal cord. (b) Radiograph taken 1.3 years after surgery showing maintenance of better spinal alignment even if sligh screw pullout from L2 vertebra 


\section{References}

1 Arciero RA, Leung KYK, Pierce JH. Spontaneous unstable burst fracture of the thoracolumbar spine in osteoporosis: a report of two cases. Spine 1989; 14: 114-117.

2 Hammerberg KW, DeWald RL. Senile burst fracture: a complication of osteoporosis. Orthop Trans 1989; 13: 97.

3 Kaneda A, Yamaura I, Kamikozuru M. Paraplegia as a complication of corticosteroid therapy: a case report. J Bone Joint Surg Am 1984; 66: 783-785.

4 Kempinsky WH, Morgan PP, Boniface WR. Osteoporotic kyphosis with paraplegia. Neurology 1958; 8: 181-186.

5 Hammerberg KW. Kyphosis. In: Bridwell KH, DeWald RL (eds). The Textbook of Spinal Surgery, Vol 2. JB Lippincott: Philadelphia 1991; pp 501-524.

6 Kaplan PA, Orthon DF, Asleson RJ. Osteoporosis with vertebral compression fractures, retropulsed fragments and neurologic compromise. Radiology 1987; 165: 533-535.

7 Maruo S, Takakuwa F, Nakano K. Paraplegie infolge von Wirbel Kompressionsfrakturen bei seniler Osteoporose. $Z$ Orthop 1987; 125: 320-323.

8 Salomon C, Chopin D, Benoist M. Spinal cord compression: an exceptional complication of spinal osteoporosis. Spine 1988; 13: 222-224.

9 Tanaka S et al. Conus medullaris syndrome secondary to an L1 burst fracture in osteoporosis. A case report. Spine 1993; 18: 2131-2134.

10 Japanese Orthopaedic Association. Criteria on the evaluation of the treatment of cervical spondylotic myelopathy. J Jpn Orthop Assoc (Tokyo) 1975; 49: addenda No. 12.

11 Denis F. The three column spine and its significance in the classification of the acute thoracolumbar spinal injuries. Spine 1983; 8: 817-832.

12 Harada A, Ueda H, Kato R, Makino H. Functional radiography for spinal fractures in osteoporosis. Proc Jpn Spine Res Soc (Tokyo) 1994; 5: 234.

13 Garfin SR, Mowery CA, Guerra J Jr, Marshall LF. Confirmation of the posterolateral technique to decompress and fuse thoracolumbar spine burst fractures. Spine 1985; 10: 218-223.

14 Abitbol JJ, Marshall L, Chesnut RM. Posterolateral spinal canal decompression for traumatic injuries. In: Garfin SR, Northrup BE (eds). Surgery for Spinal Cord Injuries. Raven Press: New York, 1993, pp 239-244.

15 McCormick PC. The lateral extracavitary approach to the thoracic and lumbar spine. In: Holtzman RNN, McCormick PC, Farcy JPC (eds). Spinal Instability. Springer-Verlag: New York 1993, pp 335-347.
16 Thevenon A et al. Relationship between kyphosis, scoliosis, and osteoporosis in the elderly population. Spine 1987; 12: 744-745.

17 Kostuik JP. Compression fractures and surgery in the osteoporotic patient. In: Frymoyer JW et al (eds). The Adult Spine: Principles and Practice, Vol 1. Raven Press: New York, 1991, pp 661-677.

18 Barlow DH. Estrogen treatment of established osteoporosis. In: Cooper C, Reeve J (eds). Spine: State of the Art Reviews. Vertebral Osteoporosis, Vol 8, Book 1. Hanley \& Belfus: Philadelphia 1994, pp 189-197.

19 Gallagher JC. Antiresorptive therapy in osteoporosis. In: Cooper C, Reeve J (eds). Spine: State of the Art Reviews. Vertebral Osteoporosis, Vol 8, Book 1. Hanley \& Belfus: Philadelphia 1994, pp 199-223.

20 Kaneda $\mathrm{K}$ et al. The treatment of osteoporotic posttraumatic vertebral collapse using the Kaneda device and a bioactive ceramic vertebral prosthesis. Spine 1992; 17: S295-S303.

21 Kaneda K, Abumi K, Fujiya M. Burst fractures with neurologic deficits of the thoracolumbar-lumbar spine: results of anterior decompression and stabilization with anterior instrumentation. Spine 1984; 9: 788-795.

22 Tomita $\mathrm{K}$ et al. Circumspinal decompression for thoracic myelopathy due to combined ossification of the posterior longitudinal ligament and ligamentum flavum. Spine 1990; 15: 1114-1120.

23 Shikata $\mathrm{J}$ et al. Surgical treatment for paraplegia resulting from vertebral fracture in senile osteoporosis. Spine 1990; 15: 85-89.

24 DeSmet AA, Robinson RG, Johnson BE, Lukert BP. Spinal compression fractures in osteoporotic women: patterns and relationship to hyperkyphosis. Radiology 1988 ; 166: 497-580.

25 Hodges SD et al. The use of transpedicular fixation in the treatment of thoracolumbar and lumbosacral spine fractures. In: Lorenz M (ed). Spine: State of the Art Reviews. Spinal FractureDislocations, Vol 8, Book 2. Hanley \& Belfus: Philadelphia, 1993, pp 287-297.

26 Krieg JC, Zuber K, Weinstein JN. Pedicle screw fixation in the thoracolumbar spine. In: Garfin SR, Northrup BE (eds). Surgery for Spinal Cord Injuries. Raven Press: New York, 1993, pp 227-237.

27 Gilbert SG, Johns PC, Chow DC, Black RC. Relation of vertebral bone screw axial pullout strength to quantitative computed tomographic trabecular bone mineral content. $J$ Spinal Disord 1993, 6: 513-521.

28 Shibata T, Yamamoto H, Kamioka Y, Iso $\mathrm{H}$. Biomechanical study of the self-setting hydroxyapatite cement injection into the vertebra with osteoporosis. J Jpn Spine Res Soc (Tokyo) 1994; 5: 336. 